\title{
Itinerario: Diseño Gráfico, Cultura Visual e identidades locales
}

Andrea Melenje Argote*

\begin{abstract}
Resumen: Itinerar es un ir y venir, viajar, re-mirar, recorrer, revisitar, transitar. Este itinerario se construye mirando desde el diseño, a través de los recorridos por diferentes contextos, en los tránsitos por diferentes perspectivas y experiencias que implican el hacer y la reflexión sobre lo proyectual. El objetivo es mirar a través de una serie de experiencias en proyectos de investigación y creación una posible ruta de trabajo y reflexión sobre el diseño gráfico y su impacto en la construcción de las identidades locales en contextos diversos. Esta perspectiva, que se construye a partir de un recorrido por diferentes rutas conceptuales y metodológicas, me ha permitido pensar el diseño como un espacio de creación comprometido críticamente con el estudio de la visualidad y las practicas culturales, aquellas que utilizan su producción como instrumento de comunicación, identificación y cohesión social.
\end{abstract}

Palabras clave: contexto - cultura visual - diseño gráfico - identidad - local - visualidad.

[Resúmenes en inglés y portugués en la página 180]

(*) Magíster en Estudios y proyectos sobre cultura visual (Universidad de Barcelona 2010). Diseñadora Gráfica (Universidad del Cauca 2008). Profesora del Departamento de Diseño de la Universidad del Cauca, Colombia.

\section{Introducción: ¿Por qué un itinerario?}

El diseño hoy se encuentra en el ojo de huracán; varios años de debates y crisis nos comprometen a pensar la importancia de reflexionar críticamente el impacto de nuestra producción en las culturas y contextos donde ejercemos como diseñadores. La experiencia de diseñar se ha trasformado de tal forma que para muchos hoy es imposible entender las lógicas y procesos que derivan en los objetos materiales, comunicaciones visuales y todo lo que hoy es denominado diseño. A partir de esto, la reflexión, la práctica, la investigación y la teoría dentro de nuestra disciplina, tendrá que dar un giro, buscando nuevas formas, perspectivas y campos de estudio que nos permitan trazar nuevas rutas y ampliar nuestras viejas preguntas.

En esta búsqueda, reflexionar sobre nuestra experiencia puede darnos pistas para trazar nuevos mapas, recorridos e itinerarios tanto a nivel metodológico como teórico, que permitan una reflexión más coherente con el momento histórico en el que nos encontramos; 
un momento en el que las prácticas y las dinámicas cotidianas están cada vez más atravesadas por la experiencia con el diseño, y la imagen termina convirtiéndose en la forma más utilizada para decirse, imaginarse, nombrarse e identificarse. Pensando en la importancia de la experiencia y en la tarea de escribir desde-sobre ella, en este artículo hago lo propio. Presento mi mapa, mi recorrido, expongo mis derivas, mis crisis, como diseñadora gráfica y profesora de diseño.

Este recorrido se construye en mi constante búsqueda por entender el sentido de nuestro hacer como diseñadores, por reflexionar el rol del diseñador en la transformación de las realidades de nuestros contextos, y por motivar en mis estudiantes una mirada crítica y sensible frente al pensar, investigar y producir diseño hoy. Léase esto como una invitación al lector; a pensar el gran reto que supone ser comunicador visual, a reflexionar sobre las dinámicas y prácticas cotidianas, a motivar la acción del diseñador que se piensa como parte de un territorio sensible, se conmueve por la imagen y las prácticas culturales que hacen parte de su contexto, y las constituye en su principal recurso en la construcción de discursos visuales comunicativos y proyectos de investigación; un profesional que participa de la producción de las formas de ver, de decir, de imaginar e imaginarse.

En este sentido propongo un acercamiento a los estudios de Cultura Visual ${ }^{1}$ como perspectiva crítica que puede posibilitarnos las herramientas conceptuales y metodológicas para el estudio de las visualidades de los contextos donde nos desempeñamos profesionalmente, y el impacto de nuestra producción en su construcción. La cultura visual se nos presenta como un campo de estudio que nos permite acercarnos a lo visual desde una perspectiva crítica y consciente del papel que juega el diseño en la construcción de las formas de ver y dotar de sentido al mundo que nos rodea. La interpretación de nuestra cotidianidad está sujeta a las diversas construcciones de sentido que creamos socialmente, de ahí la importancia y la urgencia del estudio de estos fenómenos desde nuestra disciplina. En este documento el lector se encontrará en primer lugar con un itinerario por las perspectivas de estudio y derivas a las que me enfrento en mi proceso de formación como diseñadora gráfica, en la búsqueda de construir una posición desde la cual mirar y enfrentar los retos que supone la práctica del diseño como un ejercicio de investigación y creación. En la segunda parte, se realiza una aproximación sobre las formas en que se construyen las visualidades en contextos particulares y su efecto recíproco en la producción del diseño. Siguiendo el recorrido, se realizará una reflexión que busca establecer una relación entre el diseño y la cultura visual como perspectiva teórico-metodológica para el estudio de la producción que deviene del diseño. Finalizo hablando de las posibilidades de acción del diseñador en la investigación visual y las posibles perspectivas teóricas y metodológicas que están a la mano cuando se trata de investigar desde el diseño. Para ello presento una serie de proyectos que a mi parecer ejemplifican un enfoque crítico en la investigación desde el diseño, los procesos y prácticas culturales en las que la imagen tiene presencia como lugar de construcción de subjetividades y visualidades.

Finalmente, este artículo busca enriquecer el debate sobre las implicaciones de nuestra actuación como profesionales de diseño en los contextos donde nos desempeñamos; es una invitación a pensar al diseñador como un interlocutor cultural e investigador comprometido críticamente con la reflexión constante sobre las derivas e intersticios de nuestra disciplina; sobre cómo nuestra producción repercute en la construcción de la realidad 
contemporánea y su impacto en los contextos locales. Este compromiso no solo nos implica como productores sino como receptores de las informaciones y bienes materiales que hacen parte de nuestra vida diaria.

\section{Ir y venir- entre preguntas derivas y crisis}

Casi al final de mi formación como diseñadora gráfica en el Departamento de Diseño de la Universidad del Cauca, donde ahora me desempeño como profesora, me interesé por la imagen y su relación con lo popular. Este interés surgió del encuentro con varias perspectivas y enfoques ${ }^{2}$ que desde el diseño cuestionaban una producción carente de identidad y enfocada a satisfacer las necesidades del mercado, sin tener en cuenta las particularidades de los contextos para los que se diseña. Esta preocupación sobre las implicaciones y responsabilidades del diseño en las culturas y la falta de crítica sobre el efecto del diseño en la sociedad, me llevaría a interesarme en las formas como las comunidades dotan de sentido lo visual.

Debo dejar en claro que en aquel momento tenía poca experiencia en investigación. Sin embargo, cuestionarme sobre las producciones visuales en torno a las prácticas cotidianas fue el primer derrotero para futuras investigaciones. Durante este camino, autores como Néstor García Canclini, Jesús Martín Barbero, Clifford Geertz, Maria Ledesma, Alejandro Tapia, ocuparon un lugar predominante en la búsqueda teórica e interpretativa sobre la forma en que el diseño puede participar del estudio de lo visual, como un lugar de resignificación constante en lo popular. Recorrer la ciudad, observar con detenimiento sus calles, sus plazas, sus galerías, sus imágenes, significaba el encuentro con los lugares y prácticas cotidianas, que daban sentido a mi papel como diseñadora. Empezaba a cuestionar los métodos y perspectivas con las que aprendí a diseñar, me cuestionaba el extrañamiento cultural que produce formarse con unas metodologías pensadas para otra época, otro momento histórico, otro contexto, muy diferente al mío. Cuestioné la forma y el contenido, el proceso y el resultado.

Pensar en el contexto, en lo local, en lo popular, significó una profunda crisis que me llevó a interesarme en perspectivas que, sin alejarme mucho de lo disciplinar, me permitieran entender cuáles son las lógicas que hacen posible la apropiación de lo visual en los contextos y su fuerte impacto en la construcción de las identidades locales. Tomando prestadas metodologías provenientes de la antropología, me enfrenté a procesos de reflexión relacionados con las prácticas culturales en las que la imagen es protagonista, primero con un ejercicio que buscaba presentar a través de un documento audiovisual las formas como una comunidad de la ciudad construye todo un escenario simbólico en relación a la salsa y después con un proyecto de animación en el que se recreaba la historia de un fanático de fútbol cuya vida giraba entorno a los objetos e imágenes alusivas a su club. Esta experiencia-a decir verdad un poco extraña y caótica- marcaría el inicio de un proyecto de investigación que significó una búsqueda mucho más estructurada y consciente sobre una perspectiva para estudiar e investigar las prácticas culturales desde la mirada del diseño. Este proyecto tuvo como objeto de estudio las imágenes gráficas que participan del espectáculo del fútbol profesional colombiano, su circulación, uso y resignificación en la ciudad 
de Popayán. De este modo, el interés radicaba en la construcción y en la apropiación de los discursos visuales a partir de las prácticas culturales de la cultura popular, pero lo que más me cuestionaba era ese rol, casi in-nombrado, que juega el espectador en la construcción de significados, en la construcción del sentido y la resignificación de lo que ve.

Al terminar mis estudios de diseño gráfico, y habiendo iniciado un proceso de indagación en el que la fascinación por las nuevas formas de entender las prácticas cotidianas de la mirada desde el diseño ocupaban casi todo mi tiempo, pensé en la posibilidad de buscar un campo de estudio que me proporcionara herramientas para enfrentarme a lo visual desde la investigación, que me permitiera reafirmar o cuestionar mi forma de entender el diseño, y su importancia en la sociedad actual.

Después de haber buscado por un largo tiempo encontré en la Universidad de Barcelona la maestría en Estudios y Proyectos Sobre Cultura Visual, la cual se me presentó como la mejor opción en ese momento. Al llegar a Barcelona, mi mirada sobre lo visual dio un giro, todo ello impulsado por la experiencia con los estudios de la cultura visual y las preguntas que este encuentro suponía. Me vi enfrentada al extrañamiento cultural que produce distanciarse del territorio conocido, y a los interrogantes que surgen con la emoción de la llegada a un contexto nuevo e inexplorado, con unas prácticas culturales muy distintas a las propias. Este encuentro resignificó muchas de las preguntas que estando en Colombia habían ocupado mi mirada, y me obligó a enfrentarme de una manera distinta a mi interés por la investigación visual. En todo este proceso tuve la necesidad de plantearme varios retos, que desde los estudios de la cultura visual, permitirían acercarme desde otro lugar a mi fascinación por las prácticas cotidianas del ver.

En un primer momento, indagaría sobre las tensiones que emergen de la invasión de objetos e imágenes made in china en los contextos locales y globales. Posteriormente, desarrollaría una reflexión sobre los modos de producción de la imagen digital y su inserción en lo cotidiano con un proyecto titulado la Cotidianidad hecha en pixel. Ambas búsquedas estaban motivadas por el interés de aproximarme a las formas como se producen y alimentan los discursos visuales en lo global, sus formas de apropiación en lo local y sus procesos de significación y resignificación. En el caso de las mercancías made in china, me interesó su capacidad para seducir, y los modos como escenifican y distribuyen diferentes manifestaciones culturales y prácticas simbólicas a través de su producción y circulación masiva. Por otro lado indagar sobre el pixel art y su puesta en escena en el escenario global, posibilitó la reflexión sobre las motivaciones que tenemos los diseñadores cuando producimos discursos comunicativos y la facilidad con la que nos dejamos llevar por las tendencias que en muchos casos son extrañas a nosotros y a nuestros contextos. Estudiar esta producción y su estética, supuso cuestionar los modos con los que nos enfrentamos al proceso de diseño y la necesidad de comprometernos de una forma responsable y coherente con las necesidades que tienen los usuarios de nuestros proyectos. Como nos recuerda Rick Poynor (citado por Pelta 2004):

Los diseñadores están comprometidos en nada menos que en la manufactura de la realidad contemporánea. Hoy vivimos y respiramos diseño. Pocas de las experiencias que valoramos en la casa, en el tiempo libre, en la ciudad o en la calle están libres de su toque alquímico. Absorbemos el 
diseño tan profundamente, que no reconocemos la miríada de caminos en los que nos mueve, engatusa, perturba y excita. Es completamente natural. Así son las cosas". (Poynor en Pelta 2004, p. 67)

El itinerario anteriormente descrito supone repensar las maneras como hoy los espectadores de lo visual en lo masivo damos sentido a las representaciones visuales que hacen parte de nuestras rutinas, y cómo el diseño participa de la producción visual que experimentamos en nuestra cotidianidad. Estas exploraciones teóricas eran producto del gran interés por entender las formas en que los sujetos hacemos uso de la imagen en nuestra cotidianidad y cómo este proceso se ve mediado por un sin número de dispositivos de visualización con los que participamos como nunca antes en la creación de la cultura visual actual. Esto me ha permitido acercarme a nuevas perspectivas de estudio y herramientas teóricas que indudablemente amplían la mirada y el panorama frente al diseño y su relación con la cultura visual. Reflexionar sobre mi rol como espectadora de lo visual fue algo que me confrontó como diseñadora, descolonizándome de todo aquel imaginario en donde el "diseñador" se entiende como profesional solo a través de su relación con el mercado. Por lo tanto, fue una invitación a pensar la posición del diseñador gráfico como productor de lo visual y como interlocutor en el escenario social.

\section{Diseño, visualidad e identidades locales}

Hoy las identidades de los grupos sociales se construyen cada vez menos sobre su repertorio de símbolos locales. La puesta en escena de unos y otros se hace a través de mensajes y objetos visuales que deambulan en lo global, lo cual permite la adaptación e hibridación de las culturas. Hoy en día, por ejemplo, las redes virtuales hacen que nuestro cuerpo y mente puedan estar simultáneamente en diversos lugares con un solo "click"; esta movilidad afecta por completo la forma en que veo, imagino e interpreto mi cotidianidad.

Los diseñadores juegan un papel decisivo al poner en escena discursos y artefactos visuales que en muchos casos se transforman en potentes íconos globales, que adquieren su carácter local a través de los medios de comunicación, los procesos de hibridación y los imaginarios e identidades locales. Estas relaciones producen imágenes que se alimentan tanto de lo local como de lo global. Es a partir de estos dos aspectos que podemos entender cómo se construyen y adquieren su significado las imágenes y objetos que usamos en nuestro día a día. Objetos e imágenes decorativas en muchos casos, sagrados en otros, producidas en serie y compradas en masa.

Preguntémonos: ¿hoy qué es lo propio?, y por supuesto ¿qué es lo otro?, ¿lo propio lo podemos entender solamente desde las dinámicas de lo local?, ¿cómo denominar los procesos en los cuales se apropian artefactos visuales de lo global en lo local, y de lo local en lo global? Tal vez debamos hablar entonces de lo "apropiado" en términos de mestizaje de la cultura visual.

Un ejemplo para hablar de este fenómeno puede ser el caso de las artesanías latinoamericanas; objetos e imágenes que han servido para la identificación de nuestros pueblos. Estas artesanías construidas desde la antigüedad por los artesanos nativos de Latinoamérica, 
han sido objeto de un proceso de adaptación para un público distinto al que tradicionalmente se debían. El turismo global ha permitido que estas imágenes sean deseadas por personas ajenas a estos contextos, produciendo nuevas significaciones a través de usos distintos a los que tradicionalmente se les ha dado. Según Canclini (2004), esto muchas veces ha sucedido con el visto bueno de sus productores, quienes por vender sus productos los han adaptado para que sean usados por un público más amplio, dada la acogida de sus productos en otros contextos. En este proceso de adaptación los objetos obtienen múltiples significaciones y usos.

No hay razones para pensar que un uso sea más o menos legítimo que otro. Con todo derecho, cada grupo social cambia la significación y los usos (...) estamos hablando de circulación de bienes y mensajes, cambios de significado, del pasaje de una instancia a otra, de un grupo a varios. En esos movimientos se comunican significados, que son recibidos, reprocesados o recodificados. (Canclini, 2004, p. 35).

Las necesidades estéticas inherentes a todos los seres humanos son suplidas en su gran mayoría a través de artefactos visuales, sin importar su lugar de origen. Lo que importa son los procesos de apropiación que se dan a partir del los usos, y su estudio desde el diseño nos debe permitir una aproximación a los sistemas de significación propios de cada cultura.

Vemos pues, cómo las imágenes en la sociedad actual se mueven y circulan de lo local a lo global y viceversa, y en estos tránsitos son objeto de diversos usos, resignificaciones, transformaciones, adaptaciones; son manoseadas por unos y otros, desgastadas y olvidadas. Bien lo dice Susan Buck-Morss (2005) "hoy las imágenes circulan por el mundo en órbitas descentradas que facilitan un acceso sin precedentes, deslizándose casi sin fricción a través de barreras idiomáticas y fronteras nacionales." (p.146) Esta facilidad de la imagen, para moverse y situarse en escenarios distintos, ha producido un cambio en las formas de ver de los sujetos, lo cual afecta trascendentalmente no solamente sus experiencias estéticas, sino todo el repertorio cultural e identitario de sus culturas.

La necesidad de incorporar en el escenario local imágenes de diferentes contextos, nos habla de la imperante urgencia de los actores sociales por participar de lo global. Los sujetos buscamos hacer parte de algo, una o varias formas de identificarnos, las cuales cada vez tienen menos relación con las formas de apropiación de un territorio y su repertorio simbólico. Las formas de identificación, hoy en día, están mucho más vinculadas a prácticas visuales que, además de tener un territorio específico, están atravesadas en muchos casos por lo virtual. Esta condición supone numerosas transformaciones en las formas como se construyen las identidades en las sociedades contemporáneas. Podemos estar asistiendo al nacimiento de un sujeto des-localizado, un sujeto que construye su subjetividad a partir de múltiples referentes, cuyas prácticas culturales están cada vez menos mediadas por el espacio físico que habita, un sujeto visual nómade. "Hoy imaginamos lo que significa ser sujetos no solo desde la cultura en que nacimos, sino desde una enorme variedad de repertorios simbólicos y modelos de comportamiento" (Canclini, 2004, p. 161).

Los tránsitos de la imagen en el mundo son articulados a través de los medios de comunicación y el consumo. Es innegable que a pesar del acceso a estos medios masivos de 
comunicación, las formas de entrada y salida de los objetos visuales en lo global y en lo local sean dispares, produciendo desigualdades y nuevas fronteras. ¿Quién impone lo que debe o no ser visto? Según Canclini (2004) “en vez del juego estético y económico entre productores culturales, son los intereses de las empresas dedicadas al entretenimiento o las comunicaciones, los que influyen en lo que se edita, se filma o es museificable."(p.22) los medios imponen lo que se ve y establecen las dinámicas narrativas para ver, pero hay una instancia individual y social de decisión sobre lo que se toma o se rechaza. Retomando a Canclini (2004) "Para entender a cada grupo hay que describir como se apropia y reinterpreta los productos materiales y símbolos ajenos.” ¿Qué rol juega el diseño en todo esto? El afán de los medios por interpretar qué es lo que el público quiere ver, leer, escuchar, o con qué se quiere vestir, ha generado una avalancha de narrativas visuales que en algunos casos son bien recibidas por los espectadores, $y$ en otros se convierten en objetos visuales transitorios que pasan al olvido rápidamente.

De acuerdo con una valoración reciente la retina contiene cien mil millones de células nerviosas que son capaces de realizar cerca de diez mil millones de operaciones de procesamiento por segundo. El hiperestímulo de la cultura visual moderna, desde el siglo XIX hasta nuestros días, se ha dedicado a intentar saturar el campo visual. Este proceso fracasa constantemente, ya que cada vez aprendemos a ver y a conectar de forma más rápida (Mirzoeff, 2003, p. 23).

La capacidad de dotar de significado a los objetos visuales es un derecho de los hombres: los usos, las formas de ver, no son y no pueden ser estandarizadas; ¿qué sería de nuestro mundo si así lo fueran? Esta libertad en la resignificación de lo visual supone un gran reto, un cambio en las dinámicas tradicionalistas que han rodeado su estudio, una transformación de los marcos, perspectiva y lugares desde los cuales se indaga; una revisión a criterios y conceptos, y sobre todo la configuración de escenarios de investigación inter o transdisciplinares, que amplíen los objetos y prácticas y con ello los lugares desde los que tradicionalmente se han mirado. Es insuficiente hablar de su importancia, o tratar de interpretar su funcionamiento refugiados en las academias; el reto supone establecer metodologías que permitan acercarse a los espectadores, pero no como conejillos de indias, sino como actores fundamentales en la construcción de la visualidad.

Las formas de recepción de unos u otros objetos visuales cambian de contexto a contexto, las apropiaciones de unos y otros dependen tanto de los imaginarios sociales como individuales, pero como dice Susan Buck Morss (2005) "lo global es conocido a través de lo local", por tanto es dentro de lo local donde adquiere sentido.

\section{Diseño y cultura visual}

Los estudios sobre cultura visual se nos presentan como un campo transdisciplinar en el que confluyen diferentes perspectivas relacionadas con lo visual. Es una perspectiva interpretativa que estudia los fenómenos de la visualidad ${ }^{3}$ y su transformación en los escenarios sociales. Esto implica pensar en la visualidad como un lugar para reflexionar sobre 
los procesos en los cuales los sujetos en colectivo se apropian de los artefactos visuales con los que se relacionan en lo cotidiano. Al centrar su atención en la mirada, nos ofrece todo un panorama de estudio sobre las formas, los hábitos, los códigos, los consensos y acuerdos que nos permiten tener una experiencia visual común, dentro de un contexto determinado. Al poner acento en el estudio de las prácticas culturales en las que lo visual hace presencia, nos acerca a la posibilidad de una indagación e interpretación crítica sobre las formas de apropiación, reconocimiento, disputa, negación, que hacen posible la construcción del sujeto visual y su identidad. Esto es posible debido a que los estudios sobre lo visual que se realizan desde esta perspectiva no giran en torno a los objetos o artefactos visuales por sí mismos, sino a su sentido y valor en lo cotidiano.

Todo ello hace que el estudio de la cultura visual se nos presente como un campo móvil, que tanto desde el punto de vista de las representaciones como de las tecnologías de la información y la comunicación, van dejando obsoletas unas determinadas aproximaciones a lo visual, al tiempo que recubren y expanden el contenido de las diferentes producciones que cada día se incorporan al campo que denominamos cultura visual (Hernández, 2006, p. 8).

Las perspectivas de algunos estudiosos de la cultura visual (Hernandez, Mirzoeff, Mitchell, Brea) han permitido comprender la importancia del estudio de las formas de comunicación visual que hacen parte de las dinámicas cotidianas y su repercusión en la construcción de nuestra subjetividad, desde la perspectiva del diseño. Entre las aportaciones más significativas se encuentran las del teórico Nicholas Mirzoeff, quien en su libro "Una introducción a la cultura visual" problematiza la emergencia de este campo de estudios y su repercusión en las formas de indagar sobre la visualidad, según él, "la cultura visual se interesa por los acontecimientos visuales en los que el consumidor busca la información, el significado o el placer, conectados con la tecnología visual."(Mirzoeff, 2003, p. 19) La importancia de esta afirmación radica en que pone como protagonista al sujeto que ve; asume que hay un interés por parte del observador al buscar una determinada información y en ella algún tipo de placer. Esta mirada sobre las prácticas cotidianas del ver, que cobran sentido en las relaciones que los sujetos establecemos con los medios de comunicación visual en la actualidad, nos permite pensar en la importancia de observar dichas prácticas siendo conscientes de su efecto en las formas de aprendizaje visual y en la construcción de las subjetividades e identidades.

Este énfasis que la cultura visual pone en las prácticas cotidianas de la mirada, es para mí un espacio de interacción entre este campo de estudios y el diseño gráfico. Según Guy Julier (2010) hoy la cultura, "formula, formatea, canaliza, hace circular, contiene y obtiene información. Por tanto, el diseño es más que la mera creación de artefactos visuales para usar o "leer" también interviene en la estructuración de sistemas para el encuentro entre el mundo visual y el material” (p.26). Nuestra vida está rodeada de objetos e imágenes a los cuales hemos atribuido significados en colectivo, los hacemos parte de nuestra cotidianidad a través de los usos y los cargamos de valores simbólicos cuando los incorporamos a nuestras prácticas culturales. Las formas en las que los apropiamos, los elementos que 
nos permiten decir lo que son y dotarlos de significados, o las maneras en que los invisibilizamos u ocultamos, nos permiten reconocernos como sujetos productores de la cultura y actuar como tal. Aunque sabemos que estos procesos constituyen nuestra cotidianidad, hacen falta muchos estudios que nos permitan entender las lógicas de las prácticas de la mirada y la visualidad. Como lo señala Mitchell (2009):

estamos rodeados de imágenes; poseemos una abundancia de teorías sobre ellas, pero no parecen hacernos ningún bien, saber que están haciendo las imágenes, entenderlas, no parece darnos ningún poder sobre ellas... Las imágenes como las historias y las tecnologías, son creaciones nuestras, y sin embargo se suele pensar que están fuera de «nuestro control», o por menos fuera del control de «alguien» (Mitchell, 2009, p. 13).

El estudio sobre la mirada se convierte en un factor clave de nuestro trabajo como diseñadores, pues nos enfrenta al reto de indagar sobre las manifestaciones de lo visual y las lógicas de los procesos que atribuyen significado a los bienes y artefactos visuales en las culturas, y sobre todo, los modos de producción de sentido, los usos sociales y las diferentes formas de circulación de los objetos e imágenes que devienen de la práctica del diseño.

Quienes nos interesamos por estudiar las manifestaciones de la cultura visual, compartimos la preocupación por cómo afrontar de una manera crítica las repercusiones de la cultura visual en la construcción de las representaciones sobre la identidad de los otros y de nosotros mismos, y en cómo éstas se reflejan y son un reflejo de los mediadores sociales que constituyen lo que hemos denominado en este artículo como el campo fronterizo, híbrido y en construcción de los Estudios sobre la cultura visual (Hernández, 2006, p. 15).

Desde luego, esto nos implica profundamente en nuestro rol como diseñadores y nos debe permitir repensar lo proyectual como un proceso mucho más amplio y riguroso que no solo atañe la resolución sistemática de un problema de diseño, sino como un espacio de creación reflexivo, consciente y crítico sobre lo que significa proyectar sobre una comunidad un discurso o un artefacto visual. Nos implica más allá del producto diseñado, nos responsabiliza sobre lo que pasa después de diseñar; nos invita a la investigación sobre los usos sociales de nuestras producciones, las formas en que circulan, los procesos que les dan significado y sobre todo si aportan o no a las comunidades para las que se diseñaron. En este sentido, como diseñadores gráficos y productores de imágenes tenemos que enfrentar estos escenarios en la búsqueda y en la generación de espacios de interacción y diálogo con los contextos para los que diseñamos. Estos espacios deben permitirnos salir de las fronteras y las seguridades en las que nos movemos, pues dar solución a problemas formales es algo que carece de sentido si las soluciones a las que llegamos no son importantes para nuestros usuarios. Los discursos que producimos en nuestra práctica como diseñadores no solo deben ser valiosos para nosotros mismos, sino que deben proyectarse a los escenarios sociales para que sean juzgados y valorados. 
En tanto el "instante del diseño" es el momento clave para la culturización de la producción, la continuidad de la cultura de la cotidianidad descansa en gran parte sobre las espaldas del diseño. De ahí la importancia clave de que tanto la disciplina como sus agentes profesionales concretos asuman las herencias, se transformen en sus depositarios y las incorporen a la labor de recreación de la cultura material (Chaves, Sánchez, 2001, p. 12).

El proceso de diseño debe transformarse y ampliarse hacia la búsqueda de nuevas perspectivas que nos permitan extender nuestra mirada sobre las implicaciones del diseño en la realidad contemporánea y que nos posibiliten mirar con mucha más amplitud y conciencia lo que se pone en juego al diseñar. Esto es, pensar en el productor, en el diseñador como un sujeto visual que hace parte de una cultura, y que al diseñar pone en juego un bagaje y unas prácticas culturales que se manifiestan en su producción. Los estudios sobre cultura visual se presentan como un lugar que nos permite forjar una perspectiva para acercarnos a la investigación y al análisis crítico sobre el impacto de nuestro hacer en los escenarios locales y globales. Mi interés es dejar una serie de inquietudes e interrogantes sobre los cuales me encuentro reflexionando y que creo que muchas de las referencias citadas en este documento pueden dar pistas para comenzar a resolver asuntos puntuales de nuestra profesión y nuestra experiencia. Las preguntas permiten trazar rutas y nuevos itinerarios, que en el caso del diseño hacen mucha falta, sobretodo con respecto a aquello que se pone en juego al diseñar, y las formas como los usuarios dan significado a lo que producimos. "Lo que deben preguntarse los diseñadores no es por qué un producto tiene sentido o es importante para ellos mismos sino qué historia quieren transmitir con un diseño y por qué esta historia es importante y tiene sentido para los consumidores". (Tapia, 2003, p.109)

\section{- ¿Cómo potencializar el trabajo del diseñador teniendo en cuenta el contexto en el que se desarrolla?}

La imagen tiene un efecto sobre el sujeto, le enseña a ver y a verse como parte de algo. Como productores visuales, los diseñadores gráficos colaboramos en la producción de imaginarios e identidades. Los discursos visuales que proyectamos surgen de nuestro contacto con los contextos y sus prácticas, de las cuales no podemos excluirnos. Somos ciudadanos y participamos como tal de las dinámicas de los contextos donde vivimos. La interpretación crítica de lo visual y sus formas discursivas, son también nuestra competencia y responsabilidad. Esto supone dejar de alimentar tendencias vacías y proyectar utilizando todo el repertorio simbólico de las culturas y contextos para los que diseñamos. Solo de esta forma nuestro trabajo será importante para la gente y sus culturas.

\section{- ¿Debe haber una intención política y pedagógica en la producción del diseñador?}

Reconocer que somos sujetos visuales implica ser capaces de entender los juegos de poder que participan en la creación y las políticas y pedagogías de la mirada que entran en juego al diseñar. Mirzoeff (2005) nos habla de una "epistemología del sujeto definido antes por su conocimiento que por su ser."(p.166). Conocimiento que atañe lo visual predominantemente, lo que obliga a poner la mirada sobre esas imágenes que han participado en esta construcción. "Los contrarios a la guerra, como yo mismo, observando la incesante 
corriente de imágenes de Irak, somos un buen ejemplo de sujeto visual, una persona casi abrumada por un material visual que no puede controlar, pero que no puede rehusar ver." (Mirzoeff, 2005, p.166) A esto me refiero cuando hablo de sujeto visual, a ese sujeto que ha construido su subjetividad y su conocimiento sobre el mundo, a partir de los artefactos visuales que hacen parte de su cotidianidad.

- ¿Somos conscientes de las interpretaciones que hacen los sujetos que usan los artefactos visuales que diseñamos?

La interpretación que hacemos de nuestro mundo está sujeta a diversas convenciones y negociaciones que construimos socialmente. La nueva experiencia de la visualidad implica que muchos de estos procesos de significación estén mediados por lo virtual, lo que produce inevitablemente una transformación en las lógicas de la producción, usos y significación de lo visual en los contextos. Como lo sugiere Mitchell:

las imágenes actuan como filtros a través de los cuales reconocemos y, por supuesto, confundimos a los otros. Suponen mediaciones que paradógicamente, hacen posible lo «no-mediado» y el «enfrentamiento» a todas aquellas relaciones que Raymond Willians postula como el origen de la sociedad como tal. Lo que quiere decir que «la construcción social del campo visual» tiene que ser continuamente reeditada como «la construcción visual del campo social», como un tamiz invisible o, incluso, una especie de celosía por la que pasan las figuras aparentemente no-mediadas, revistiendose con ese efecto de mediación que las caracteriza (Mitchell, 2003, p. 34).

Los sujetos construyen sus identidades en un espacio de tensiones, entre los arraigos a un territorio y los vínculos con una sociedad mediatizada donde lo visual es protagonista.En un contexto híbrido como el nuestro, conviven formas de comunicación orales, escritas, virtuales, etc, lo cual implica un grado de responsabilidad mayor para el diseñador, exigiendo un trabajo reflexivo constante sobre las lógicas de comunicación de las comunidades para las que se diseña, sobre sus repertorios simbólicos y practicas culturales."Lo que necesitamos es una crítica de la cultura visual que permanezca alerta ante el poder de las imágenes para bien y para mal, capaz de discriminar entre la variedad y especificidad histórica de sus usos" (Mitchell, 2009, p. 10).

Dar respuesta a esta cuestión implica pensar en perspectivas de investigación que nos permitan el estudio de las formas como se asientan los artefactos visuales en un contexto determinado, su valor y los procesos que permiten que los sujetos y sus culturas les atribuyan significado.

\section{Diferentes proyectos, miradas compartidas}

Recientemente ha surgido un creciente interés en nuestra disciplina por desarrollar nuevas perspectivas sobre cómo se investiga en diseño, (Frayling, Pontis, Archer, Bell, Laurel, Luton) esto hace parte de un proceso que implica replantear los viejos paradigmas metodológicos y sus enfoques, apuntando al desarrollo de perspectivas interdisciplinares y 
colaborativas que permitan ampliar los lugares desde lo cuales se ha investigado y reflexionado disciplinariamente.

En el contexto Colombiano, hay pocas instituciones que se han tomado en serio el abordaje metodológico e investigativo en sus curriculums, y esto sumado a los pocos espacios donde se debate sobre la investigación, dificulta mucho más la posibilidad de concretar una perspectiva propia que nos permita consolidar proyectos con impacto y largo aliento. Las experiencias de investigación son reconocidas y divulgadas, pero esto no es suficiente si no se reflexiona sobre esos procesos y su aporte a la disciplina. Esto implica una profunda reflexión sobre los diferentes lugares desde los cuales se investiga, las perspectivas utilizadas, los posibles objetos de investigación, los enfoques metodológicos y las estrategias de socialización de los proyectos y sus procesos.

La investigación en diseño debe ser pensada, debatida, experimentada y consolidada dentro de las escuelas y departamentos de diseño. No solamente como parte de la exigencias de los entes gubernamentales, sino como un espacio donde se recree y resignifique nuestra mirada. La responsabilidad de las instituciones donde se enseña diseño es promover la reflexión sobre la investigación como un proceso creativo que incluye la intervención, la producción, la interacción social, la generación de ideas y nuevas perspectivas metodológicas.

El diseñador debe formarse para producir discursos y artefactos que permitan a los sujetos tener experiencias valiosas en su cotidianidad, ser interlocutor en el escenario social y consolidarse como investigador de los procesos de recepción, uso, circulación y apropiación de lo visual. Se debe buscar en su formación un fortalecimiento de su postura crítica y reflexiva sobre las formas en que su producción afecta las realidades de los contextos y sobre todo prepararle para ser un sujeto comprometido con las políticas y pedagogías de la mirada.

Siguiendo esta idea, y para terminar, presento cuatro proyectos de investigación-creación, desarrollados por estudiantes y profesores del Departamento de Diseño de la Universidad del Cauca, en dos de los cuales participo directamente como investigadora. Estos proyectos han sido el resultado de una búsqueda por acercarse desde el diseño al contexto, a sus dinámicas y prácticas culturales. Estas iniciativas pueden darnos pistas sobre la formas en las que el diseño puede investigar las visualidades de los contextos y sus particularidades. Las perspectivas de indagación a continuación esbozadas son el resultado de una posición frente al diseño, que se construye en la búsqueda constante por ampliar y renovar nuestra mirada disciplinar.

\section{La ruta del guarapo (2009-2011)}

Investigador: Germán Salamanca

Esta propuesta surge dentro del proyecto de investigación Cauca Contemporánea del grupo interdisciplinario de investigación de la Universidad del Cauca Artes 2000. Se enmarca dentro de la línea de trabajo Estéticas Populares, que acoge investigaciones en torno a la configuración del gusto popular en la región. Entendiendo lo popular como la contraparte a las concepciones hegemónicas de identidad y cultura. "La ruta del guarapo" indaga en torno a las prácticas culturales derivadas de las dinámicas de producción y consumo del 
guarapo en las veredas de Puelenje y Torres, en el Municipio de Popayán.

En la investigación se desarrolló una perspectiva histórica en la que se llevó a cabo una rigurosa consulta a diferentes referentes bibliográficos, con el fin de enmarcar y comprender las dinámicas económicas, sociales y culturales bajo las cuales se etiquetaron estas prácticas, que desembocaron en la persecución de las mismas. De la misma forma, se realizó un trabajo de campo con diferentes actores de la comunidad involucrados en la producción y consumo del guarapo en las veredas de Puelenje y Torres. Esto con el fin de recopilar elementos vivenciales que permitieron dilucidar factores claves para comprender los diferentes elementos que configuran dichas prácticas.

El investigador construye una perspectiva metodológica que se estructura como un recorrido sensible en el cual él cartografía los lugares donde se asienta esta práctica cultural, y las formas como se constituye en un patrimonio de la cultura popular. La investigación se formula bajo esta mirada, permitiendo que el diseñador que investiga se enfrente al planteamiento teórico del proyecto con un alto grado de sensibilidad frente a la forma de poner en contexto su investigación. Este proyecto pone de relieve la importancia del trabajo de campo para poder desarrollar el concepto gráfico de su propuesta. Enfatiza en que es desde aquí desde donde es posible desarrollar una propuesta visual que logre evidenciar la mirada desde el diseño y generar una lectura del imaginario, para luego desdoblarla en un lenguaje visual pertinente o acorde con las características del contexto. En este sentido, Germán Salamanca planteó una serie de nociones claves como: la ruta, la cartografía, el viaje, lo vivencial, la memoria, llegando finalmente a la libreta de apuntes. Esta conceptualización le permitió generar una pieza gráfica que evoca el sentido cartográfico e infográfico de la investigación.

"La ruta del guarapo" es un proyecto de investigación que hace visibles las prácticas culturales que nos inscriben en un contexto diverso, es un diálogo con el entorno desde la perspectiva del diseño que nos permite ver al diseñador como un investigador que construye memoria sobre nuestro patrimonio cultural.

\section{Fútbol, imagen y espectador (2006-2008)}

Investigadores: Rafael Sarmiento López - Andrea Melenje Argote

Este proyecto fue un acercamiento a la formas de apropiación, usos y resignificación de la producción visual relacionada con el fútbol colombiano desde la mirada del diseño. De manera específica la indagación se focalizó en la visualidad que se recrea en la gráfica referente al fútbol que circula en las clases populares, tratando de establecer conexiones entre aspectos sociales, simbólicos y territoriales que a nuestros ojos establecen las diferentes relaciones de sentido que están latentes en estas imágenes, y que a su vez configuran la mirada y el sentir del hincha en la ciudad de Popayán.

La indagación buscó estudiar las estéticas que están presentes en dichas imágenes, los discursos que en ellas hacen presencia y las formas de apropiación de esta producción por parte de los espectadores. Para ello se realizó una investigación teórica y de campo, que en primer lugar nos permitió establecer conexiones entre las imágenes y las formas de construcción y validación del gusto popular en nuestro contexto; en segundo lugar, 
a través de la etnografía, se logró establecer contacto con los espectadores, quienes nos permitieron ver las formas como son usadas estas imágenes en su cotidianidad y su valor como artefactos simbólicos.

Este proyecto tomó cuerpo en dos productos: un ensayo y una exposición itinerante que recogió y presentó los diferentes momentos de la investigación. El ensayo, al igual que la exposición, se estructuró en tres momentos que pueden ser leídos de manera paralela:

Fútbol y ciudad busca dar cuenta de los elementos simbólicos que hacen del fútbol un fenómeno cultural de gran importancia en nuestro contexto, y en especial propone a Popayán como un escenario donde el fútbol y la imagen gráfica que hace parte de éste, ocupa un lugar protagónico en la cotidianidad y en las formas de vivir la ciudad. Responde al lugar donde se enmarcan y se desarrollan los hechos que se observaron en la investigación. Imagen y discursos se acerca a la importancia que tiene la imagen gráfica que hace parte del fútbol como generadora de discursos y marcas, que configuran los imaginarios y las identidades de los individuos.

En Espectadores y Sentidos, se busca darle voz a los espectadores que dan testimonio de los procesos de resignificación a los que está sujeta la imagen y los sentidos que los espectadores le otorgan de acuerdo a su usos.

Este proyecto nos permitió reafirmar nuestro interés de observar y analizar los tipos de comunicación visual que hacen parte de nuestra cotidianidad y comprender la gran responsabilidad que una profesión como la nuestra tiene en la investigación de los fenómenos visuales que hacen parte de nuestras culturas.

\section{De carácter y caracteres. Una aproximación a la letra Gótica, sus usos y su apropiación por los Ultras en el Fútbol. (2009)}

Investigador: Rafael Sarmiento López

El proyecto buscó ejemplificar cómo a partir del uso y la apropiación de la letra se re-crean visualidades en contextos específicos. El investigador busca poner en cuestión el paradigma de la transparencia tipográfica en el diseño, desde una perspectiva que propone una serie de relaciones de sentido entre la letra, el tipografismo, la cultura pop, el consumo cultural, y las subculturas. Esto es posible a través del abordaje teórico de fuentes bibliográficas y recursos visuales que le permiten construir un posicionamiento reflexivo sobre las formas como se ha abordado el estudio de la letra desde la perspectiva disciplinar. La propuesta plantea una revisión a los marcos académicos desde los cuales se piensa la letra, esto según el investigador nos debe permitir aproximarnos a la tipografía desde distintos lugares, para comprender cuáles y cómo son sus usos sociales.

Este proyecto desarrolla un abordaje crítico sobre las formas como se apropia la tipografía gótica en diferentes contextos y por diferentes colectivos. Estudia los modos de apropiación de esta tipografía y su connotación en el escenario de las barras bravas o ultras en el fútbol colombiano, a través de sus usos. Esta indagación nos permite acercarnos a una perspectiva de investigación que se construye a partir de la revisión de carácter teóricohistórico y etnográfico. 
El documento de esta investigación permite ver la posición crítica del investigador frente la producción del diseño, su vínculo con un territorio específico y las prácticas culturales que transforman su sentido a partir de as diferentes formas de apropiación y usos. Utilizando como ejemplo los procesos de incorporación de la letra gótica en la barras bravas o ultras en Colombia, nos habla de las maneras en que se transforman los artefactos visuales cuando se relacionan con los escenarios simbólicos en los diferentes momentos de la historia.

\section{Talleres de ilustración (2010-2012)}

Investigadores: Rafael Sarmiento López - Andrea Melenje Argote

Este proyecto es el resultado de muchas conversaciones, discusiones y experiencias, que en últimas reiteran nuestra preocupación sobre la imperante necesidad de repensar y reflexionar las perspectivas y metodologías que ponemos en práctica cuando enseñamos a diseñar. Esta perspectiva nos llevaría a plantear la importancia de remirar muchos de los paradigmas sobre la enseñanza del diseño y su aplicación en nuestro contexto, y a pensar en la posibilidad de desarrollar una propuesta de creación que nos permitiera acercarnos a la educación visual a través del diseño. Partiendo de estas premisas construimos un itinerario que buscaba comenzar a trazar una ruta de trabajo con la intención de fomentar experiencias sensibles frente a la producción visual a partir de la ilustración y la expresión. Pensamos la ilustración como un espacio que nos permite la exploración de múltiples lenguajes y posibilidades de representación visual; creemos que la expresión gráfica en nuestra disciplina es un terreno que necesita ser observado con detenimiento y revisado partiendo del estudio de las experiencias que, en la actualidad, transforman radicalmente las relaciones de los sujetos frente a lo visual. Esta perspectiva nos permitió ver en el componente de expresión del programa de Diseño Gráfico de nuestra universidad un terreno que nos abría el panorama de la creación y experimentación con recursos diversos, un espacio de producción sensible que nos permitiría reflexionar sobre muchas de las premisas metodológicas y teóricas, que para bien o para mal, condicionan nuestra experiencia en la clase, y proyectar un laboratorio de investigación-creación que nos acercara a construir escenarios de aprendizaje partiendo del diseño.

De esta forma, surge la propuesta de talleres de ilustración, como un proyecto enfocado en la necesidad de propiciar espacios de aprendizaje visual con diferentes comunidades, buscando alentar la reflexión sobre la importancia de la producción visual como lugar de recuperación y activación de la memoria, como un recurso para contarse, construir y definir identidades. Nuestra motivación principal con este proyecto es repensar críticamente las formas de enseñanza de lo visual hoy, " en unos tiempos inciertos y para unos sujetos en tránsito, para quienes aprender resulta con frecuencia una obligación y en muy pocas ocasiones una experiencia apasionante" (Hernández, 2007, p. 25).

La educación visual y proyectual está siendo repensada desde múltiples enfoques (Hernández, Freedman, Duncum, Margolin, Lupton, Pericot, Calvera) que nos permiten ver la posibilidad de construir modelos educativos mucho más coherentes con las condiciones 
sociales de nuestra región y las comunidades que la habitan. El Cauca es un Departamento muy particular, tanto por las condiciones geográficas y la riqueza natural de su territorio, como por la condición pluriétnica y multicultural de sus comunidades. Es además una región azotada por la violencia y por la inequidad social, lo que la configura como un escenario en el que fenómenos como el narcotráfico, el desplazamiento forzado y la violencia de género, hacen fuerte presencia. Pensando estas particularidades, vimos la necesidad de promover espacios alternativos de educación visual desde el diseño, que nos permitieran entrar en diálogo con diferentes actores sociales y comunidades de nuestra región, a partir de la creación, para facilitar el intercambio de experiencias y promover la recuperación de la memoria por medio de la representación.

Nuestro objetivo principal es consolidar espacios de encuentro en los que podamos interactuar con niños, niñas, jóvenes y adultos de nuestro contexto mediante talleres de ilustración, y a partir de la experiencia de aprendizaje visual reflexionar sobre las formas de ver de los sujetos dentro y fuera del aula. Así, el taller de ilustración narrativa se consolida como un esfuerzo conjunto entre un grupo de estudiantes y profesores ${ }^{4}$ del programa de Diseño Gráfico de la Universidad del Cauca. Partiendo del concepto del kit, el taller acerca a los participantes a la representación visual con recursos diversos a partir de relatos y experiencias de vida. Este taller ha logrado consolidarse como un espacio de creación y experimentación propicio para el diálogo con diferentes comunidades y colectivos dentro y fuera de nuestro país.

El proyecto talleres de ilustración busca proyectarse como un espacio de intercambio donde participantes y talleristas se encuentran para compartir sus experiencias y producir narrativas visuales sobre sus prácticas culturales más valoradas. Esta perspectiva implica poner sobre la mesa la reflexión sobre la pedagogía como un lugar que permite el reconocimiento y aprendizaje del mundo. Nos interesa construir una "narrativa que considere que lo pedagógico no se reduce a una simple práctica de enseñanza y aprendizaje, sino que es también una práctica política. Lo que implica estar en guardia frente a los discursos que tratan de dibujar, bajo la apariencia de neutralidad y objetivismo, visiones del mundo y representaciones del sujeto que excluyen y marginan muchas de las representaciones identitarias existentes" (Hernández, 2007, p. 38).

\section{Notas}

1. Según Fernando Hernández (2010) la "cultura visual se nos presenta como una trama teórico-metodológica deudora del postestructuralismo, los estudios culturales, la nueva historia del arte, los estudios feministas, entre otras fuentes, que pone énfasis no tanto en la lectura de las imágenes como en las posiciones subjetivas que producen las imágenes esto significa considerar que las imágenes y otra representaciones visuales son portadoras y mediadoras de posiciones discursivas que contribuyen a pensar el mundo y a pensarnos como sujetos y que, en suma, fijan la realidad de como mirar y ser mirados" (p. 16).

2. Desde inicios del año 2000, comienzan en Colombia a emerger proyectos de creación e investigación que desde el diseño y las artes visuales se interesan por visibilizar e indagar sobre las manifestaciones gráficas de lo popular y su arraigo en nuestras culturas. Algunos de 
estos grupos y colectivos interdisciplinares más representativos fueron: Excusado printsysten, Popular de lujo, Ninja Pingüino y G15 de la universidad Nacional de Colombia.

3. La visualidad la podemos entender como la construcción social de la mirada, según Hernández (2005) "el concepto de visualidad, que tendría como adjetivación la noción de social, en contraste con lo que sería el estudio científico de la visión, cuestiona la idea de universalidad y progreso en el arte de ver. Bajo esa perspectiva nos interrogamos sobre lo que nos hace sensibles a las culturas visuales ajenas a nuestros propios hábitos y normas de ver y de mirar, y las de diferentes periodos y lugares" (p. 18).

4. El planteamiento y ejecución del taller de ilustración narrativa fue posible por el apoyo de un grupo de estudiantes y profesores del Departamento de Diseño de la Universidad del Cauca a quienes agradecemos por su compromiso y esfuerzo: Leandro Triana, Juana Zúñiga, Sebastian Martínez, Jhon Mera, Felipe Castaño, Sergio Astaiza, Magenta Paz, Juan Arboleda, Carlos Manquillo, Felipe Fernandez, Marcos Camacho y Miguel Tejada.

\section{Referencias Bibliográficas}

Barbero, M.(2003). De los medios a las mediaciones. Bogota: Gustavo Gili.

Brea, J. (Ed.). (2005). Estudios visuales. La epistemología de la visualidad en la era de la globalización. Madrid: Akal.

Chaves, N. Sanchez, A. (2001, abril). El patrimonio gráfico y su recuperación. Tipográfica. $\mathrm{n}^{\circ} 47$.

Freedman, K. (2006). Enseñar la cultura visual. Currículum, estética y la vida social del arte. Barcelona: Octaedro.

García Canclini, N. (2005). Diferentes, desiguales o desconectados. Barcelona: Gedisa.

(2001). Consumidores y ciudadanos. Mexico: Grijalbo.

(2001). Culturas Híbridas, Estrategias para entrar y salir de la modernidad. Argentina: Paidos.

Geertz, C. (1990). La interpretación de las culturas. Barcelona: Paidos.

Hernández, F. (2010). Educación y cultura visual. Barcelona: Octaedro.

(2007). Espigador@s de la cultura visual. Otra narrativa para la educación de las artes visuales. Barcelona: Octaedro.

(2006). Los estudios de cultura visual: La construcción permanente de un campo no disciplinar. La Puerta. Publicación de Arte y Diseño. 2. Pp. 87-97.

(2005, julio). ¿De qué hablamos cuando hablamos de Cultura Visual? Educaçâo e Realidade. Recuperado de: seer.ufrgs.br/educacaoerealidade/article/download/12413/7343

Julier, G. (2010). La cultura del diseño. Barcelona: Gustavo Gili.

Ledezma, M. (2003). El diseño gráfico una voz pública. Buenos Aires: Argonauta.

Mirzoeff, N. (2003).Una introducción a la cultura visual. Barcelona: Paidos.

Mitchell, W. J. T. (2009). Teoría de la imagen. Madrid: Akal.

(2003, noviembre). Mostrando el ver: una crítica de la cultura visual.Estudios visuales. Recuperado de: http://estudiosvisuales.net/revista/pdf/num1/mitchell.pdf

Pelta, R. (2004). Diseñar hoy. Temas contemporáneos de diseño gráfico. Barcelona: Paidos. Tapia, A. (2004). El diseño gráfico en el espacio social. México DF: Designio SA de CV. 
Summary: Itinerate is a coming and going, traveling, watching, walking, visit, travel. This itinerary is built from the design looking through tours of different contexts, transits by different perspectives and experiences that involve making and reflecting on the design project. The aim is to look through a series of experiences in research and creative projects a possible route for work and reflection on graphic design and its impact on the construction of local identities in different contexts. This perspective, which is constructed from a tour of different conceptual and methodological routes has allowed me to think about design as a creative space committed to critically study the visual and cultural practices, those that use their output as an instrument of communication, identification and social cohesion.

Keywords: context - graphic design - identity - local - visual culture - visuality.

Resumo: Itinerar é um ir e vir, viajar, re-mirar, recorrer, re-visitar, transitar. Este itinerário se constrói mirando desde o design, através dos recorridos por diferentes contextos, nos trânsitos por diferentes perspectivas e experiências que implicam o fazer e a reflexão sobre o projetual. O objetivo é mirar através de uma série de experiências em projetos de pesquisa e criação de uma possível rota de trabalho e reflexão sobre o design gráfico e seu impacto na construção das identidades locais em contextos diversos. Esta perspectiva, que se constrói a partir de um percurso por diferentes rotas conceptuais e metodológicas, me permitiu pensar ao design como um espaço de criação comprometido criticamente com o estudo da visualidade e as práticas culturais, aquelas que utilizam sua produção como instrumento de comunicação, identificação e coesão social.

Palavras chave: contexto - cultura visual - design gráfico - identidade - local - visualidade. 